\title{
"Dynamics of Rules and Resources: Three New Field Experiments on Water, Forests and Fisheries"1
}

\author{
Juan-Camilo Cardenas (Universidad de Los Andes-Colombia) \\ Marco Janssen (Arizona State University-USA) \\ Francois Bousquet (CIRAD-France)
}

\begin{abstract}
Chapter submitted for a "Handbook on Experimental Economics and the Environment" edited by John List and Michael Price (Edward Elgar Publishing).
\end{abstract}

\begin{abstract}
.
Most common-pool resource experiments, inspired by the ground-breaking work of Ostrom, Gardner and Walker (1994), involve a typical structure of a static non-linear social dilemma with a rival but nonexcludable good that is extracted by a number of players. However there are specific ecological features of relevant common-pool resources that can be incorporated into an experimental design and tested in the field or the lab. Stock effects, spatial effects or vertical downstream externalities are issues that natural scientists and economists have studied in forests, fisheries or watershed management although experimental works on these ecological aspects are rather scarce.

We designed three resource specific games to capture particular characteristics of common-pool resources and apply them in six villages in Thailand and Colombia. In each village we recruited 60 people and conducted three games. A water irrigation game capturing the downstream externalities and collective action problem of provision and appropriation stages where all players need to contribute to a public project that produces water which is then extracted sequentially by each of the players starting with the one located upstream, leaving the remaining water to the next player downstream, and so on. In our forestry game players start with a number of standing trees that can be cut by any of the players; in any round each player can extract between zero and a fixed number of trees. The remaining trees regrow at a certain rate and the resulting trees are then left for the next round for individual extraction. The game ends at a maximum number of rounds or when no trees are left. Finally, the fisheries game involves two possible fishing sites that can have high or low levels of stock. Each player needs to decide where to fish between the two sites and her individual effort of fishing. Depending on the aggregate level of fishing effort in each site, the stock level will change for the following round and will determine the fishing returns. All games involve a social dilemma where individual interests clash with the socially optimal outcome. Lessons can be derived regarding the design of better resource management rules and a better understanding of how resource specific dynamics affect the social dilemmas in commonpool resources.
\end{abstract}

\footnotetext{
${ }^{1}$ The authors wish to thank the NSF grant within the HUMAN AND SOCIAL DYNAMICS PROGRAM for their funding. More details about the research project can be found in: http://www.public.asu.edu/ majansse/dor/nsfhsd.htm
} 


\section{Introduction and motivations for a new wave of experimental designs}

The last few decades have witnessed an increase in the use of experiments for the study of various environmental and natural resource phenomena (Sturm and Weimann, 2006; Cherry et.al, 2007). Much of this work involves a better understanding of the behavioral foundations of decision-making when facing environmental externalities and uncertainties, and a more careful understanding of how incentives and institutions affect such decisions and their environmental outcomes.

On one area of work, several economists and psychologists have made significant contributions to the study of how behavioral particularities of humans may affect society's value of resources and the environment. A vast literature has studied the problems of biases involved in economic valuation studies, and thanks to behavioral approaches and experimental techniques, better explanations and calibration methods now exist to improve these valuations thanks to seminal works by Kahneman, Tversky and co-authors (See Kahnemann et.al. 1990 and Horowitz and Macconnel, 2002). We now know better about discounting future benefits and costs within alternative behavioral approaches, or the valuation of environmental losses as opposed to environmental gains (See Shogren, 2004 for a survey) and the risk attitudes towards uncertain outcomes, including environmental risks.

Another branch of experimental work applied to environmental and resource issues involves the study of how incentives and institutions affect decisions and outcomes. Experimentalists have used experimental designs to study how markets fail or achieve social efficiency and how different instruments or incentives aimed at correcting the market failure can improve outcomes. These designs include the design and analysis of water management systems and markets (Cummings et.al. 2003, Ward et.al 2006), network markets for resource allocation (e.g. energy network markets, Denton et.al. 2001), or marketable permits for pollution (Murphy and Stranlund, 2006 and 2007) and external regulations including taxes and subsidies.

A third group of experiments have focused on the typical problems of group externalities or social dilemmas associated with common-pool resources and public good issues with direct applications to resource and environmental issues. Ledyard's survey (1995) of experiments on the voluntary contributions mechanism to study public goods problems originating in the 1980s work by economists and psychologists such as James Walker, Mark Isaac, R.Ames, and G.Marwel and Ostrom, Gardner and Walker (1994) for the case of common-pool resources, are probably the most significant seminal works that generated a stream of experimental variations to understand the behavioral and institutional foundations of why would people, despite the clear incentives to free-ride, engage in cooperative behavior and refrain from overexploiting a common-pool or contribute voluntarily to the provision of a public good. Field experiments in this area include Velez et.al 2008 and 2008; Cardenas et.al 2000; 2002; 2004; Rodriguez et.al 2008.

Further, most of these studies have involved university students as their experimental subjects, and only a few have been applied in the field with non-student samples. Field experimentalists from various disciplines in social and natural sciences have expanded the wealth of research by heading to the field and run experiments with subjects that are familiar with the problem in 
question. The richness from expanding the demographic variation of the subject samples was also enriched by including more explicit framings to the protocols in order to better connect the experiment with the context of the participants.

However, when evaluating the experimental literature that has studied environmental and resource issues, we can see that most of the motivations and inputs in the designs have come from behavioral and institutional concerns, and less from the characteristics of the ecosystem, its functions and its resource dynamics. The externalities have remained for most of the cases as symmetric, linear and with only one dimension of interdependence. Most public goods production functions and externalities have been linear, and most common-pool designs have maintained the simplicity of a quadratic function of benefits on group effort.

This has been a wise decision at a time when the behavioral predictions from the economic literature needed to tackle the problem of the very weak empirical and laboratory support for the selfish free-riding prediction. By keeping the production function externalities and dynamics simple, experimentalists have been able to tackle the main issues with respect to social dilemmas and behavior that have been contributing to the literature about cooperation, trust, reciprocity and pro-social behavior in general. We now know that reciprocity plays a major role in explaining behavior of individuals in social dilemmas, that free-riding is a strategy chosen by only a small fraction of players, that players do respond although partially to pecuniary incentives and that individuals are altruistically willing to contribute to a public good or refrain themselves from over extracting a common-pool either because they care about the others, inequality or the environment per se.

Meanwhile, the natural resource, environmental and ecosystem management literature has provided for a long time enough evidence that understanding the ecosystem functioning needs to be incorporated into the study of human-ecosystem interactions (Clark, 1976). Maybe it is time for a next step and introduce also the ecological complexities of the social dilemmas in environmental and natural resource problems into the behavioral analysis. With this paper we propose a next wave of experimental designs to augment the knowledge that the experimental literature has brought to environmental and resource economics.

In particular, we believe that the following aspects of ecosystems can be introduced into these new experimental designs. The first particularity of resources is its dynamics over time. Most resources availability to humans depends to the stock situation in previous rounds and experiments can incorporate such feature in various ways. Also there are asymmetries with respect to watershed management where the externalities flow unidirectionally across players from upstream to downstream agents, but not vice versa. Additionally, watershed management suffers from two inseparable issues involving a collective action dilemma: provision and appropriation. Individuals face a conflictive dilemma at the provision level for the production, maintenance and distribution of water, and another dilemma in the appropriation of the resource itself. Also, some resources (e.g. fisheries) are used by humans making simultaneously decisions about effort and location and such decisions interact in a more complex way (the tragedy of the commons can be triggered either by a spatial decision, an effort decision or by the interaction of the two).

And finally, we want to highlight the fact that for a great deal of ecosystems and regions were natural resources are economically and ecologically valuable, the stakeholders or decision 
making agents are villagers with certain degrees of education levels, cognitive abilities and socio-economic characteristics that vary much more than in the case of a group of college students. Also, these villagers have a longer experience of trial and error making resource extraction decisions than the usual student. Therefore, we have chosen the strategy to head to the field lab and conduct our experiments with stakeholders that face this reality of ecological and economic complexities on a daily basis.

\section{Ecosystem dynamics, individuals and institutions}

When it comes to the governance of social-ecological systems, one size does not fit all (Young, 2002). Experience from the governance of system $X$ cannot directly be implemented in system Y. As proposed by Ostrom (2007), we need to develop a diagnostic framework to identify the relevant components of social-ecological systems in terms of resource dynamics and resource governance. Such a diagnostic framework likely will consist of nested layers of more detailed attributes of social-ecological systems that are not relevant for all social-ecological systems.

From a systematic comparison of case studies, Schlager et al. (1994) and Janssen et al. (2007) both identified the main distinction in types of resources with regard to self-governance of common pool resources: whether the resource units are mobile (fishery, pastoralism), or whether infrastructure is developed to guide the resource flow (irrigation systems, internet). In performing experiments of decision making in commons dilemmas, we should distinguish explicitly the resource dynamics.

There is substantial literature on the fit between institutions and ecological dynamics (e.g. Young, 2002). An institutional arrangement that works perfectly for one resource problem might be a dismal failure if applied to another resource problem (Acheson, 2006). This would not be as problematic if there were clear classes of case studies instead of the heterogeneity in ecological and social processes we observe in the world around us.

An innovation we made in previous years is to include ecological dynamics more explicitly in resource experiments in the lab (see Janssen et al. in press; Janssen and Ostrom) and the field (this chapter). So, what are the main ecological dynamics to include? It is nowadays widely recognized that ecosystems dynamics is complex. Concretely, watershed are governed by interactions between upstream and downstream inhabitants for water flows, the spatial interactions between fishermen and fish population as well as the ecological interactions among the multiple species lead to unpredictable dynamics, multiple forest resources such as $\log$ trees or non timber forest products have very different ecological dynamics and are exploited by different stakeholders. In his paper on ecosystem complexity, Holling (1987) defines three concepts that have dominated causality in ecological systems and that define the principles for the management of ecosystems. The first one is based on the notion of equilibrium (balance of nature), the second one defines several states of stability (nature engineered or nature resilient). This second perception is interested in dynamics caused by variability, by events that occur at small scales. The third point of view is the one of organizational change (nature evolving). The system changes: external events lead to perturbation of the system, but also, especially when human beings are part of the system, the actors of the system may, by themselves, change the organization of the system. This third point of view corresponds to the approach adopted by the sciences of complexity: the general 
state of a set of interacting entities may converge toward attractors, may be disordered, or may exhibit patterns of organization that change from one to another in an unpredictable way (Wolfram, 1984; Langton, 1992). There is a need to take into account both the resource dynamics and the heterogeneity of stakeholders. Very often these two questions were addressed separately, either exclusively from the point of view of "an ecological system subject to human disturbance" or, alternatively, from the point of view of "a social system subject to natural constraints". In the first case, scientists make a careful description of the dynamics of the resource, with management constituting a definition of the various forms of exploitation which can be sustained over the long term by this resource. Social dynamics are summarized in terms of the type of resource exploitation they entail. In the second case, researchers generally concentrate on the problem of resource use, considering homogenous economic agents who share the same rationality. The perception of the collective is not taken into account.

Models are considered as very useful tools to integrate social and ecological dynamics. Several authors have been using agent-based models in the field of ecosystem management for many years. This kind of application was begun by Lansing and Kremer who studied water management in Bali, Bousquet et al. for fisheries management (1993), Deadman and Gimblett (1994) for park management, and Kohler and Carr (1996) for archeological issues, Janssen (1999) for lake management and Dean et al. (2000) and Balmann (1997) for agricultural land management. If we view ecosystems in terms of people and management problems, Epstein and Axtell (1996) study the structuring of networks and their effect on the management and distribution of resources. In a more applied context, we note the studies of Antona et al.(1998) on the organization of economic exchanges between harvesters of renewable resources and consumers. Barreteau and Bousquet (2000), Feuillette et al (2003) and Mathevet et al. (2003), among others, propose models and simulations that involve relations among one or more natural resources, agents who can individually exploit the common land and act on the common resource, and sets of interactions between agents who coordinate their actions or exchange information. A good overview is given in Janssen and Ostrom (2006).

A good starting point is to look at existing experimental designs that have addressed the problems of ecological externalities and resource problems. In traditional common pool resource experiments the payoff structure is based on a static game where each round plays as a fresh new game with exact same conditions. It would be more relevant and externally valid to led the state of the resource be dependent on the actions of the participants in the previous rounds, as well as on local conditions surrounding the specific resource. Regarding the payoffs function, common-pool resource games have traditionally used a payoffs function that is concave on the group effort, while public goods have often used a linear one, but in both cases the strategic game remains within a static context with no interdependence between the payoffs structure of one round to the next.

The major innovation in the experimental design here proposed is adding more ecologically relevant dynamics of the resource. The experiments discussed in this paper will include some basic dynamics like multiple equilibria, renewal rates, asymmetry of access, but will not include variability. We decided to develop three kinds of experiments which mimic in an abstract way key ecological dynamics relevant for forestry, fishery and irrigation. As described in the next section, our experiments will include:

- non-linear behavior of the resource, e.g. in the relationships between effort, resource stock and returns from effort 
- $\quad$ asymmetry of access to the resource, e.g. because of the upstream-downstream location of resource users

- space, e.g. in the relation between location and resource stocks

- path-dependency due to the dynamic interactions, e.g. a resource availability at a given time $t$ highly dependent on decisions previously achieved

\section{Our design for 3 games}

In the previous section we discussed the importance to include more relevant ecological dynamics in studying the ability to overcome common pool resource dilemmas. We have developed three kinds of experiments representing dilemmas in forestry, fishery and irrigation. In this section we discuss the general design of the experiments and the three typological, and how we have organized the experiments.

Since we aimed at designing an experiment that could be implemented in the field with stakeholders that in their daily lives face the kind of dilemmas and dynamics we want to study, we needed to develop a simple pencil and paper design to be used in a field setting where participants have a wide range of formal education levels and cognitive abilities. After a two year period of pretesting designs we were able to head to the field for the final experiments here reported. The complexity of ecosystems included are very stylized, but well understood by the participants with the design developed.

The experiments were held in six villages in Thailand and Colombia: three in Thailand and three in Colombia. The villages were selected to represent a dominant resource use of one of the three resource appropriation activities: fishery, forestry and irrigation. In Thailand experiments were performed in the Petchaburi watershed, which is located in the West of Thailand, in three separate locations. One of the locations in the coastal area, and the other two in the inland. The Colombian experiments were conducted in three different rural sites. The fishery community is represented by a village on Barú Island, (rural area of Cartagena city, in the Caribbean coast). The irrigation community is located in the Fuquene lake basin area, located in the Andean region of Cundinamarca and Boyacá. And the forestry community is located in the Pacific coast tropical forest area.

For all these locations permission were given when needed by the head of villages to perform experiments. The experiments were held during the first 6 months of 2007. Typically four days of experiments were followed by in depth interviews with a sample of relevant stakeholders of the village.

In each village each of the three resource games was conducted with 4 groups of 5 people. As a result 360 individuals have participated in the experiments according to Table 1.

[Insert Table 1 here] 
The general outline of the experiments is as follows ${ }^{2}$. In each experiment 5 individuals participate. They may know each other, but they do not know the decisions of the other individuals during the experiment. Only the aggregate outcomes of the decisions are presented to the group. They are not allowed to communicate with others during the experiment. Assistants are available during the experiments for those participants who have difficulty with reading and/or arithmetic. After instructions and practice rounds, the participants will play 10 rounds. They are not told the number of rounds in advance. After the $10^{\text {th }}$ round, three different rules are presented for which one can vote to be implemented in a subsequent series of rounds. The three rules represent a property type of rule, a lottery type of rule, and a rotation type of rule, and are all aimed at solving the resource dilemma. The participants turn in their vote, and are asked to fill out a brief survey on their opinions about characteristics of the rules, before the result are announced. If two rules get two votes, an additional round of votes between those two candidates is used to define the final chosen rule.

Ten rounds are played with the new rule implemented. The first round after the election has the same starting situation as round 1 of the experiment. Before the participants receive their payments, they fill out a general survey on their demographics and resource use within the village. The duration of an experimental session was about 3 hours and the typical earnings of the participants was one day of labor.

The participants were recruited via word of mouth and flyers hanged throughout the village, and participants of 18 years and older could participate. Special emphasis was done to recruit adults from households engaged in the resource extraction of that village. Only one member of a family was allowed during the same session. At the end of the series of experiments a handful of people were identified for in depth interviews. Those individuals were selected among the participants to receive a representative sample of the community. At the end of the week, a session was organized to discuss the experiments and their situation in relation to natural resources.

\section{a. Forestry Game}

The key feature of the forestry game is the renewable component of the stock of timber. The stock is represented as 100 magnets, trees, on a board. In each round participants can take a maximum of 5 magnets from the board. The stock will regenerate. For every 10 magnets on the board, one magnet is added, with a maximum of 100 magnets. When the stock is below 25 trees, the maximum number of magnets each individual is allowed to extract is given by the following table:

\section{[Insert Table 2 here]}

When participants collect as much as possible as fast as possible, the stock will be depleted in 5 rounds, and the tokens collected by the group is 119 . When they cooperate and maximize the group earning the group total can increase to 165 (figure 1), for a sequence of 10 periods or rounds.

\footnotetext{
${ }^{2}$ See the field protocols in the Appendix.
} 
[Insert Figure 1 here]

After ten rounds the participants can vote for one of the three following rules:

- Rule 1 (Lottery). Each round two participants are drawn who can harvest. If somebody harvest when (s)he is not allowed to do so, a penalty may be received. Each round a dice is thrown, and when a six is through, an inspector comes and rule breakers get a penalty. The penalty consists of paying back the harvested amount plus an extra 3 tokens.

- Rule 2 (Rotation). A fixed schedule is defined which two participants are allowed to harvest each round are able to harvest. In round $1 \mathrm{~A}$ and $\mathrm{B}$ can harvest, then $\mathrm{C}$ and $\mathrm{D}$, then $\mathrm{E}$ and $\mathrm{A}$, etc. The same mechanism of monitoring and sanctioning is used as rule 1.

- Rule 3 (Property). Everybody has the right to harvest 0, 1 or 2 units per round. If a higher amount is harvested, a dice determine whether the participant is caught, pays back the harvest plus 3 tokens.

\section{b. Water Irrigation Game}

In the irrigation game participants get each round 10 tokens and have to make first a decision how much to invest in a public fund that generates water for the whole group to share; then each player, in sequential turns from upstream to downstream players decide how much to extract from the generated water. Each token kept (not invested) has a monetary value for the player, and is equal to the value of each unit of water extracted.

Participants have positions A, B, C, D or E, where A has the first choice to harvest water from the public good. This game includes the dilemma of upstream participants who need the help of downstream participants to generate a favorable size of the public good. However, the downstream participants can only get benefits from the public good when upstream participants avoid the temptation to deplete the common resource and leave water for players downstream.

Under this asymmetric game, participants first experience a public goods game in the contributions stage, and then face a resource appropriation dilemma when they extract from the generated resource, creating once again a common pool resource problem. In Table 3, the water provision generated is defined as a function of the total investments of the five participants. Clearly under these incentives and rules, the Nash equilibrium is that nobody invest in the water provision, and all receive 10 tokens for a group earnings of 50 tokens. In the cooperative (social optimum) solution, everybody invests her 10 tokens in the public good, producing 100 units of income in each round. Therefore, for a sequence of 10 rounds, the group earnings would sum 500 tokens and a social optimum could go up to 1000 tokens. 
[Insert Table 3 here]

After 10 rounds the participants can vote on one of the following three rules:

- Rule 1 (Lottery). Each round the order in which participants can collect from the common resource is randomly drawn after everybody has made their decision how much to invest in the water provision.

- Rule 2 (Rotation). There is a fixed rotation system of the order in which people can collect from the common resource, starting with $\mathrm{ABCDE}$ in round 1, then BCDEA, etc.

- Rule 3 (Property rights): Each participant receives the right to use 20 percent of the common resource. The order to extract water remains the same for all the rounds: ABCDE. A dice is thrown in each round. When 6 is thrown, participants who collect a higher amount than the share of 20 percent have to pay back the excess water harvested, and also pay a penalty of 6 additional tokens.

\section{c. A Fishery Game}

In the fishery game participants decide each round where to fish and how much effort to exert. There are two locations $\mathrm{A}$ and $\mathrm{B}$ they can choose to go to, and they can choose to exert low or high levels of effort. There is a slightly higher return from a high effort compare to a low effort (see Table 4 below). The payoff table is the same for both locations, and the initial state of the resource is the high fish availability. However, when the total effort in a location is five or more units, the state of the fish stock will move to the low availability. This situation can only be reversed when in two consecutive rounds not more than one unit of effort is invested in that location. When participants behave opportunistically they move to the low state of both resources in two rounds, and get stuck in that situation for the remainder of the rounds. For a sequence of 10 rounds, this opportunistic behavior will result in 200 tokens for the 5 people group. However, if they would be able to coordinate their efforts, the cooperative solution leads to 382 tokens by spreading the effort equally over the two resources where at least two people do not exert the maximum effort.

[Insert Table 4 here]

After ten rounds the participants can vote for one of the following three rules:

- Rule 1 (Lottery). Each round the location where each of the participants is allowed to fish is randomly determined by throwing a dice for each participant. When a participant harvest in a location illegally, a throw of a six of the dice leads to paying back the harvest points. 
- Rule 2 (Rotation). Each round one of the location is banned from fishing: A in rounds 1 and 2, B in rounds 3 and 4, etc. If a participant is caught fishing illegally the harvested amount need to be returned.

- Rule 3 (Property right): Each participant can exert an effort of 0 or 1 per round. In case a participant is caught putting two units of effort, the participant need to pay back the harvested amount.

\section{Field results: patterns of behavior and outcomes.}

\section{a. Our participants.}

The field experiments for this study were conducted during the first semester of 2007 in Thailand and Colombia, with 360 villagers invited to voluntarily participate in 72 sessions, and we avoided having in the same session two people from the same household. In each country we conducted 12 sessions for each game. Each villager participated in only one session of 5 players and 20 rounds which took about 2-3 hours including instructions, game decisions, payment and ex-post individual interviews to collect basic household data and a set of questions regarding the experiment.

The average age of our participants was 39 years (Std.Dev 14.6), and 34 percent of them were females. About two thirds of them reported living in that village for their entire life. Their households were in average of 5 members (also the modal household size), with less than 10 of households having 2 or less members and 10 percent of households with 8 or more members. The education level of the participants varied as well. 7 percent of them had no formal education, and about 30 percent of them with some or complete primary education. 47 percent of the players had secondary education and only some 12 percent received technical or university training. About 82 percent of them reported owning some land.

At the end each participant was paid in private according to the tokens earned in its respective game, plus an additional show up fee. In average each player earned the equivalent to 1-2 days wage for her participation in a 2-3 hours session.

\section{b. Choices and outcomes in the games.}

The results here reported illustrate how our three game designs can offer new insights to the understanding of the complex relationship between experimental behavior and particular 
ecological features we incorporated into the three games described before. Some of these patterns seem robust although were unexpected

We will conduct the analysis in the following manner. For each of the games we will describe the patterns of individual and group behavior and study how it affected the individual and group earnings over time. Recall that every session included 10 periods or rounds under a baseline treatment where players could not communicate with each other, and a second sequence or stage of 10 more rounds where they had the chance to vote for one of three possible rules (lottery, rotation or property rights) and face the voted rule with a imperfectly enforced regulation that would punish non compliance. In all cases the groups were told by the experimenter that the rule was aimed at regulating the way the resource was harvested and/or who would have the right in each round to harvest it (See protocols in the appendix).

Before we present the results for each of the games, let us briefly summarize the main overall patterns observed.

First of all the data suggests that once again the Nash prediction of selfish maximizers of individual tokens is not a good predictor for the average player in these experiments. Although there is a minority of players that do followed a strategy of extracting the maximum possible of units of the resource, such fraction of players did not seem to reflect the majority nor it invaded as an evolutionary strategy the rest of players. On the other hand we do not observe either a trend towards the maximization of the group outcomes during the first or the second stage under the voted rules.

Overcoming the temporal and spatial ecological features of the resource dynamics proved to be a difficult task both with and without rules to govern extraction levels and assignment of rights to the resource users. As it will be shown later, the dynamic effects of the forestry and fishery games imposed a difficulty for the players who found it quite difficult to recover back higher levels of the stock which could substantially increase earnings.

With respect to the rules implemented during each of the sessions we observed that they had a weak but positive impact over behavior and outcomes. The first rounds after the rule was implemented in each of the games did show a change towards more cooperative behavior across all games and sessions, the dynamics of the behavior and the resource seemed to shift the group behavior towards a similar equilibrium achieved before the rule was applied, with some exceptions and qualifications to be discussed below. For instance, the rules helped to improve substantially the distribution of earnings across the players in the watershed location.

\section{c. Field results for the Forestry Game.}

Our forestry game starts with a resource stock of 100 trees and where 5 players can extract from 0 to 5 trees in each round, unless limited by the available stock according to Table 2 . In each round, after extraction, every 10 standing trees will yield one more tree that is available to the group for extraction. The two graphs below (Figures 2 and 3) summarize the observed behavior and the resulting outcomes for the forestry game. Figure 2 shows the mean and 95 percent confidence interval for the levels of harvest or trees extraction by individuals over time, and for the two stages of the game. 
[Insert Figure 2 here]

The first stage (rounds 1-10) clearly show that most groups start from a high level of individual extraction of about 4 units which is slowly reduced by only one unit halfway in round 5 . However, with a group extraction (forest depletion) oscillating between 15 and 20 units, the growth rate of the resource of 10 percent of standing stock would not allow for much recovery of the forest creating a much difficult setting for balancing renewal and extraction, as it can be seen in Figure 3 where we graph the available stock of the resource in each round. Notice that at round 5 about half of the forest stock has been depleted. In general the rate of decrease in extraction overrides the capacity of re-growth of the resource.

\section{[Insert Figure 3 here]}

The second stage does show a different pattern. The two graphs suggest that with a lower initial levels of extraction somewhere between 2 and 3 units per player the resource stock is sustained for a longer period (by round 15 about 75 percent of the trees are standing) and by the end of the second stage most of the sessions showed that our participants left somewhere between 20-40 percent of the trees. In fact notice that by the end of the first stage the confidence interval suggests that a significant number of groups did not deplete entirely the forest by round 10, although they did know that the stage would be stopped by this round.

Comparisons across the two countries during the first stage show no major difference which would suggest that the game induced a robust behavior regardless of the context or culture, for the baseline case. However it is interesting to notice that a very small but valuable difference in the very first rounds after the rule $(t=11-13)$ help to provide much better conditions for a more sustainable extraction of the forest in the Thailand case (Fig.3) and substantially higher stock levels by the end of the final round $(t=20)$. This illustrates one of the points we have highlighted about the importance of studying these non-linearities and dynamics of the ecological conditions of the resource within our experimental designs ${ }^{3}$.

\section{d. Field results for the Water Irrigation Game.}

The irrigation game involves two individual decisions, namely, provision and appropriation of the resource (i.e. contributions from 0 to 10 tokens to the public fund that produces water, and extraction from the available water units in each upstream-downstream location). Water produced and available for the group to extract is based on Table 3. Figure 4 shows the average and 95 percent confidence interval for the levels of contributions by all players in each round, and for the two stages before and after the rules were introduced. From the start of the

\footnotetext{
${ }^{3}$ The plausible explanations for the observed difference across the two countries are not explored here and will be the subject of analysis elsewhere.
} 
first stage the Thailand sessions show lower higher levels of contributions for the production of water for the group. The decrease over time of such contributions, consistent with baseline voluntary contributions or public goods experiments seems to be present, especially for the Colombian sessions. In figure 5 we show the final average earnings for the players for this game. Recall that final earnings are the sum of the tokens not invested in the public fund and water units extracted by the individual, and that the exchange value of each of the units (kept or extracted) is the same.

[Insert Figure 4 here]

[Insert Figure 5 here]

In both cases we observe a similar pattern of decrease in the level of social efficiency due to the lower contributions to the public fund which in turn produce less water for the group as a whole, according to Table 3 in the design. In fact the rules did not have a positive impact. On the contrary, the individual earnings for the second stage decreased from an average of 17.43 units per round per player to 15.34 units ( $p$-value $=0.0256$, Mann-whitney $p$-value $=0.0062$ ) for the entire sample.

However, the more striking result for the change from the first to the second stage is the dramatic improvement in the distribution of water from upstream players to downstream players. In the figure 6 we report the average water units extraction in each of the locations in the watershed and compare the first stage (rounds 1-10) to the second stage (rounds 11-20). While in the first stage players A and B were concentrating most of the water leaving those downstream with much less of the resource available, the second stage witnessed a redistribution that improved the earnings of players $\mathrm{D}$ and $\mathrm{E}$ at the end of the sequence.

[Insert Figure 6 here]

The losses in efficiency seem to be compensated by the gains in distribution. It is necessary, however, to explore the reasons why the rules were so ineffective in this case to increase contributions to the public good, and if other rules could bring the efficiency and distribution hand in hand to the groups. 


\section{e. Field results for the Fishery Game.}

In our fishery game each payer could exert an individual effort of 0,1 or 2 units in one of the two possible sites A or B. Therefore the group effort in the two sites ranges between 0 and 10 units for the 5 players involved in any particular round. Such group effort would be distributed between the two sites. The returns or fishing harvest per effort unit from each site would depend on the stock level of that particular site, according to Table 4. Further, the stock level (Low or High) of one site depended on the aggregate effort exerted in that site in the previous round.

Figure 7 shows the mean group effort in each country of our sample with its respective 95 percent confidence interval. Two main results are easily observed. The ineffectiveness of the rules in the second stage as no major change is observed across stages (a Mann-Whitney test comparing rounds $8-10$ with rounds $11-13$ or 11-20 shows no significant difference, $\mathrm{p}$ value $=0.3181)$. Also, Colombian groups apply a higher effort to the fishery if compared to the Thailand cases. The difference in the group means is of about one unit of effort, with a pvalue $=0.000$.

\section{[Insert Figure 7 here]}

As a result, group earnings (See Figure 8) could not be sustained at high levels after the third round both before and after the rules were applied. For the second stage higher earnings were sustained for an extra round or two but such improvement did not last. The reason is that the group efforts on both sites $\mathrm{A}$ and $\mathrm{B}$ were sufficiently high to bring both sites to the low level of stocks as required by Table 4. Recovering back from low to high stocks of fisheries was very difficult. Figure 9 shows precisely this problem by graphing over rounds the percentage of groups from our sample that had a high fish stock for each of the sites A and B with a clear pattern of decrease in available stocks over time and very few cases of groups that were able to recover back to high stock levels. Notice that both before and after the rules by the third round only around 30 to 40 percent of the groups still showed high stock levels.

[Insert Figure 8 here] 


\section{Lessons: What did we learn from applying these games in 6 villages in Colombia and Thailand?}

Forests, watersheds and fisheries are key resources that provide benefits to societies around the world. Most of these resources are exploited by human groups of different levels of socioeconomic and demographic levels who need these resources for their daily lives. The interactions within these human groups and between the groups and their ecosystems require the understanding of the ecological and economic systems involved. We contribute to this challenge by designing new experiments and apply them in the field in villages where resource users face these interactions between ecological functioning and economic incentives.

Our new experimental designs were aimed at incorporating a set of ecological complexities to standard economic experiments regarding a social dilemma in the use of a common-pool resource or the provision of a public good. These ecological complexities are well documented in the literature and by adding them into new experiments we can now augment our knowledge about behavior in the laboratory regarding environmental and natural resource issues. We adapted existing games from the common-pool resource and public goods games literature and designed a set of three games for these particular problems to address complexities such as resource dynamics (forestry and fishery games), spatial effects (water irrigation and fishery game) and non-linearities (all three games).

By bringing these three designs to the field in 6 villages in Colombia and Thailand were a substantial fraction of villagers would depend on the use of common pool resources such as these, we added to the issue of external validity and tested some predictions regarding the behavior of economic agents who derive direct benefits from the extraction of these resources while facing the "tragedy of the commons".

The results provide some lessons about the potential of these designs for providing further insights into the understanding of the human-ecosystem interactions. From our sample of 72 sessions we could find no evidence of groups confirming the hypothesis of selfish maximizers of monetary payoffs which would drive the individuals to the tragedy in all three games. No group was able either to achieve the group optimal outcome.

In the forestry game exhaustion of the resource as predicted in the Nash strategy of Figure 1 did not happen. In the water irrigation game contributions to the public fund were above the zero prediction and in average all five players had the opportunity to get some water from upstream players, although the selfish Nash prediction is for players not to contribute and therefore to produce no water for the group to extract. In the fishery game not all players chose their maximum possible effort, although their decisions still had a large impact on the stocks in each of the sites.

These are not striking news to the experimental literature, and we expected so since our design wanted to resemble the basic social dilemma condition of this literature. Meanwhile, our designs can help us analyze the impact of individual and group on the resource stock and on 
the earnings of the players because of the features introduced in the designs ${ }^{4}$. For instance, a small difference in the forestry group extraction in the first rounds seems to have a lasting effect in the possibilities to sustain the possibility of extracting trees over time because of the path dependency of the resource dynamics; the same case was observed for the fisheries' stocks because of the group efforts and the difficulty to recover back the high levels of the stock.

Both in the case of the forestry and the water irrigation games we observed that groups did not exhaust the resource entirely, leaving some units in the ground, that is, money was left in the table. In the forestry game the average number of standing trees in the last period of each stage was significantly above zero (See Figure 3), and significantly higher in the last round of the second stage. In the case of water, the average last player $(\mathrm{E})$ in the downstream sequence did not extract all remaining units (a simple test shows that the water extracted as percentage of available water for player $\mathrm{E}$ is statistically different from 100 percent).

Overcoming the fisheries trap is a major puzzle in our fishery game. Once a group fell in the low stock, there were individual attempts to decrease effort but these were not sufficient to sustain for two rounds a low group effort in that site and allow for its recovery back to high stock levels. Again, we did not observe that all players were following a selfish strategy, and several players were choosing only 1 unit of effort instead of the 2 allowed. Further, why not even under rules for allocating more evenly the efforts among the two sites were the groups able to recover back from low stocks of fish in each of the sites? We believe such trap is related to the non linear relation between group effort and group payoffs in a particular site. The marginal opportunity cost from decreasing group extraction in one unit was not constant across the levels of group effort. Bringing group extraction to the required levels for the recovery of the stock was much more expensive in terms of foregone income if we compare to higher group effort levels. Next variations of the game could explore the sensitivity of the result to changing the relative payoffs between 1 and 2 units of efforts, or the number of rounds required to induce the change from low to high stocks or viceversa.

Hopefully with these new games we can contribute to a new wave of experimental designs that augment the wealth of research on the interactions between behavior and institutions by adding the ecological features of ecosystems into tractable models and controlled settings both for the lab or the field.

\footnotetext{
${ }^{4}$ The application of the rules in average had rather minor impacts, although such effect varied within countries across sessions. The effectiveness of each of the rules is not evaluated here and left for another study, as well as explanations of the higher levels of pressure over the resources for the Colombian cases of most of the games.
} 
Bibliography.

Acheson, J.M. (2006) Institutional Failure in Resource Management, Annual Review of Anthropology 35: 117-134

Antona, M., F. Bousquet, et al. (1998). "Economic Theory of Renewable Resource Management: a Multi-Agent System Approach." Lecture Notes in Artificial Intelligence 1534(1534): 61-78.

Balmann, A. (1997). "Farm based modelling of regional structural change. A cellular automata approach." European Review of Agricultural Economics 24(1): 85-108.

Barreteau, O. and F. Bousquet (2000). "SHADOC: a Multi-Agent Model to tackle viability of irrigated systems." Annals of Operations Research 94: 139-162.

Bousquet, F., C. Cambier, et al. (1993). "Simulating the interaction between a society and a renewable resource." Journal of Biological Systems 1((1)): 199-214.

Cardenas, J-C, and Elinor Ostrom "What do people bring into the game? experiments in the field about cooperation in the commons", Agricultural Systems, 2004, Vol 82/3 pp 307326.

Cardenas, Juan-Camilo, John K. Stranlund and Cleve Willis. 2002. Economic Inequality and Burden-Sharing in the Provision of Local Environmental Quality. Ecological Economics 40(3), 379-395.

Cardenas, Juan-Camilo, John K. Stranlund and Cleve Willis. 2000. Local Environmental Control and Institutional Crowding-Out. World Development 28(10), 1719-1733.

Cherry, Todd L. , Stephan Kroll, Jason F. Shogren (2007) "Environmental Economics, Experimental Methods". Routledge.

Clark, C. (1976). Mathematical Bioeconomics. New York, Wiley

Cummings , Ronald C., Charles A. Holt and Susan Laury (2003) "Using Laboratory Experiments for Policy Making: An Example from the Georgia Irrigation Reduction Auction”. Andrew Young School of Policy Studies Research Paper Series No. 06-14.

Deadman, P. and H. R. Gimblett. (1994). "A Role for Goal-Oriented Autonomous Agents in Modeling People-Environment Interactions in Forest Recreation." Mathematical and Computer Modelling 20(8): 121-133.

Dean, J., G. Gumerman, et al. (2000). Understanding Anasazi culture change through AgentBased Modeling. Dynamics in Human and Primate societies. T. Kohler and G. Gumerman, Oxford University Press: 179-206. 
Denton, M., S.J. Rassenti and V.Smith (2001) "Spot market mechanism design and competitivity issues in electric power". Journal of Economic Behavior \& Organization, Volume 44, Issue 4, April 2001, Pages 435-453.

Epstein, J. and R. Axtell (1996). Growing Artificial Societies. Social Science from the Bottom Up, Brookins Institution Press/ The MIT Press.

Feuillette, S., F. Bousquet, et al. (2003). "SINUSE: a multi-agent model to negotiate water demand management on a free access water table." Environmental Modelling and Software 18(5): 413-427.

Holling, C. S. (1987). "Simplifying the complex: the paradigms of ecological function and structure." European Journal of Operational Research 30: 139-146.

Horowitz, John K. \& McConnell, Kenneth E., 2002. "A Review of WTA/WTP Studies," Journal of Environmental Economics and Management, Elsevier, vol. 44(3), pages 426-447, November.

Janssen, M. A. and S. R. Carpenter (1999). "Managing the Resilience of Lakes: A multi-agent modeling approach." Conservation Ecology 3(2).

Janssen, M.A., J.M. Anderies and E. Ostrom (2007a) Robustness of Social-Ecological Systems to Spatial and Temporal Variability, Society and Natural Resources 20(4): 307-322

Janssen, M.A. and E. Ostrom (2006), Governing Social-Ecological Systems, Handbook of Computational Economics II: Agent-Based Computational Economics, Edited by L. Tesfatsion and K.L. Judd, Elsevier Publisher, pp. 1465-1509

Janssen, M.A., and E. Ostrom, TURFs in the lab: Institutional Innovation in dynamic interactive spatial commons, Rationality and Society, in press

Janssen, M.A., R.L. Goldstone, F. Menczer and E. Ostrom, Effect of rule choice in dynamic interactive spatial commons, International Journal of the Commons, in press

Kahneman, Daniel \& Knetsch, Jack L \& Thaler, Richard H, 1990. "Experimental Tests of the Endowment Effect and the Coase Theorem," Journal of Political Economy, U.Chicago Press, vol. 98(6), pages 1325-48, December.

Kohler, T. A. and E. Carr (1996). Swarm based modelling of prehistoric settlement systems in southwestern North America. Archaeological applications of GIS, UISPP XIIIth Congress, Forli, Italy.

Langton, C. G. (1992). Life at the edge of chaos. Artificial Life \{II $\}$. C. G. Langton, C. Taylor, J. D. Farmer and S. Rasmussen, Addison-Wesley: 41-91. 
Lansing, J. S. and J. N. Kremer (1994). Emergent properties of Balinese water temple networks: coadaptaion on a rugged fitness landscape. Artificial life III. C.Langton. Santa $\mathrm{Fe}$, Addison-Wesley.

Mathevet, R., F. Bousquet, et al. (2003). "Agent-based simulations of interactions between duck population, farming decisions and leasing of hunting rights in the Camargue (Southern France)." Ecological modeling 165(2/3): 107-126.

Murphy, James J. and John K. Stranlund. 2007. "A Laboratory Investigation of Compliance Behavior under Tradable Emissions Rights: Implications for Targeted Enforcement." Journal of Environmental Economics and Management 53(2), 196-212.

Murphy, James J. and John K. Stranlund. 2006. "Direct and Market Effects of Enforcing Emissions Trading Programs: An Experimental Analysis." Journal of Economic Bebavior and Organization 61(2), 217-233.

Ostrom, E. (2007) A diagnostic approach for going beyond panaceas, Proceedings of the National Academy of Sciences 104(39): 15181-87.

Ostrom E., Gardner R. and Walker J. (1994), Rules, Games and Common-Pool Resources, University of Michigan Press, Ann Arbor, 1994.

Rodríguez-Sickert, Carlos , Guzmán , R.A. and Cárdenas, J.C.(2008) "Institutions influence preferences: evidence from a common pool resource experiment”. Forthcoming Journal of Economic Behavior and Organization.

Schlager, E., W. Blomquist and S.Y. Tang (1994) Mobile Flows, Storage, and Self-Organized Institutions for Governing Common-Pool Resources, Land Economics 70(3): 293-317

Shogren, Jason (2004) Experimental Methods and Valuation, Handbook of Environmental Economics (K.-G. Mäler and J. Vincent, eds.) Elsevier: Amsterdam 2004.

Sturm, Bodo and Joachim Weimann (2006), Experiments in Environmental Economics and some Close Relatives, Journal of Economic Surveys 20(3), 419-457.

Velez, Maria Alejandra; John K. Stranlund and James J. Murphy. 2008. "What Motivates Common Pool Resource Users? Experimental Evidence from the Field." Forthcoming Journal of Economic Behavior and Organization.

Velez, Maria Alejandra; James J. Murphy, and John K. Stranlund. 2008. "Centralized and Decentralized Management of Local Common Pool Resources in the Developing World: Experimental Evidence from Fishing Communities in Colombia." Forthcoming in Economic Inquiry.

Young, O.R. (2002) The institutional dimensions of environmental change: Fit, interplay and scale, MIT Press, Cambridge, MA 
Ward, J. Tisdell, J.G., Straton, A. and Capon, T., An empirical comparison of behavioural responses from field and laboratory trials to institutions to manage water as a common pool resource. IASCP 2006 proceedings, Bali Indonesia, 2006.

Wolfram, S. (1984). "Cellular automata as models for complexity." Nature 311: 419-424. 
Figures and Tables

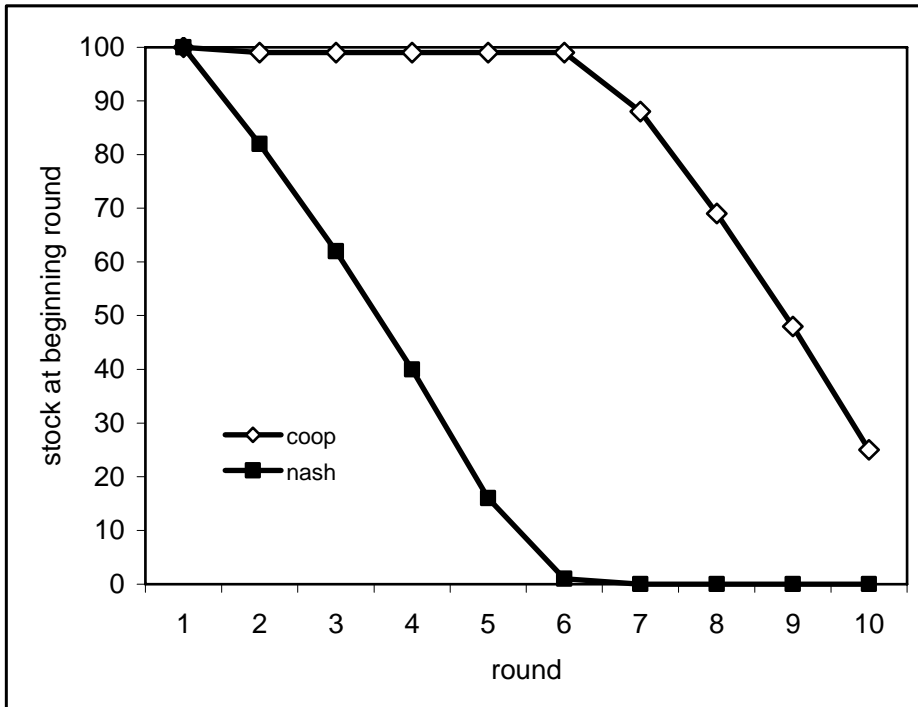

Figure 1: Cooperative optimum and Nash equilibrium (Forestry game).

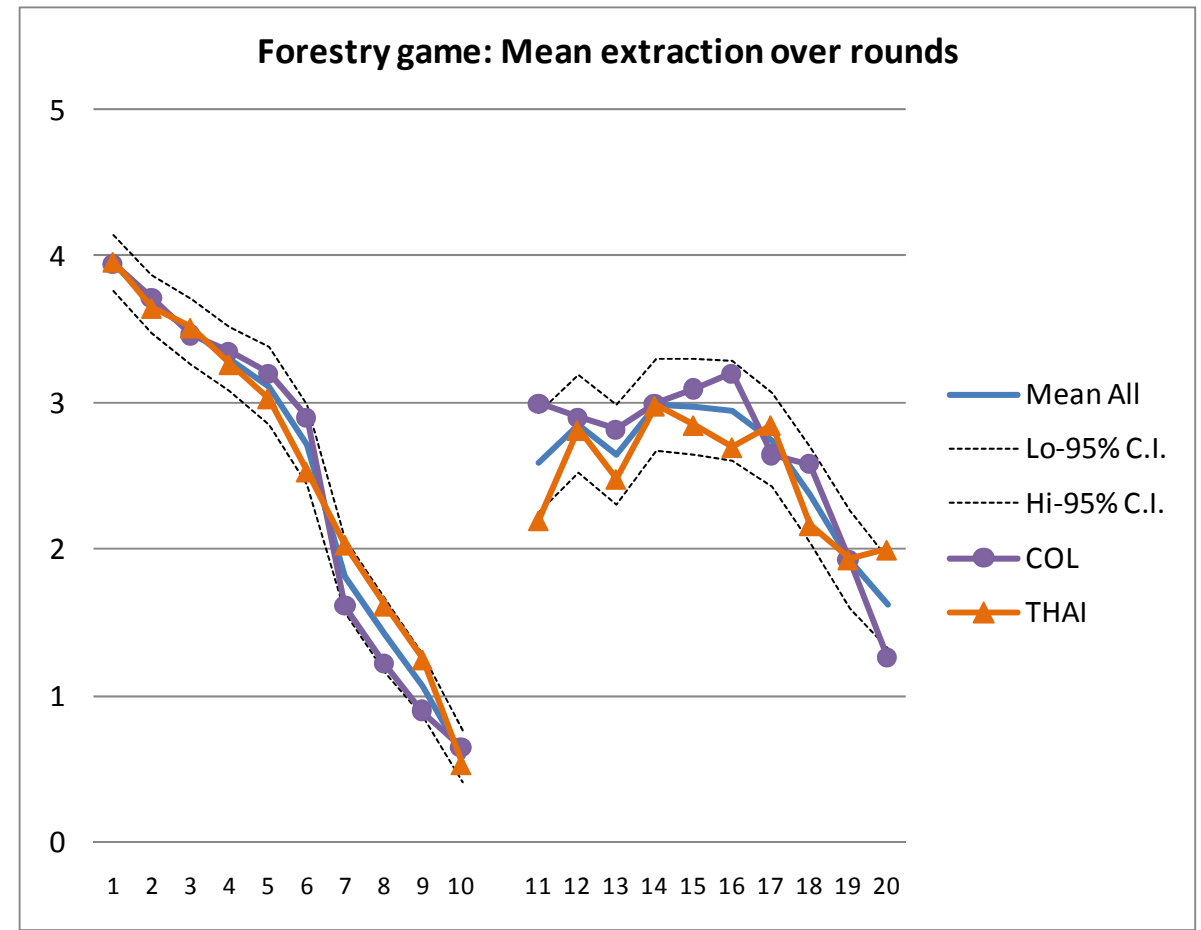

Figure 2. Forest harvest over rounds (Forestry game) 


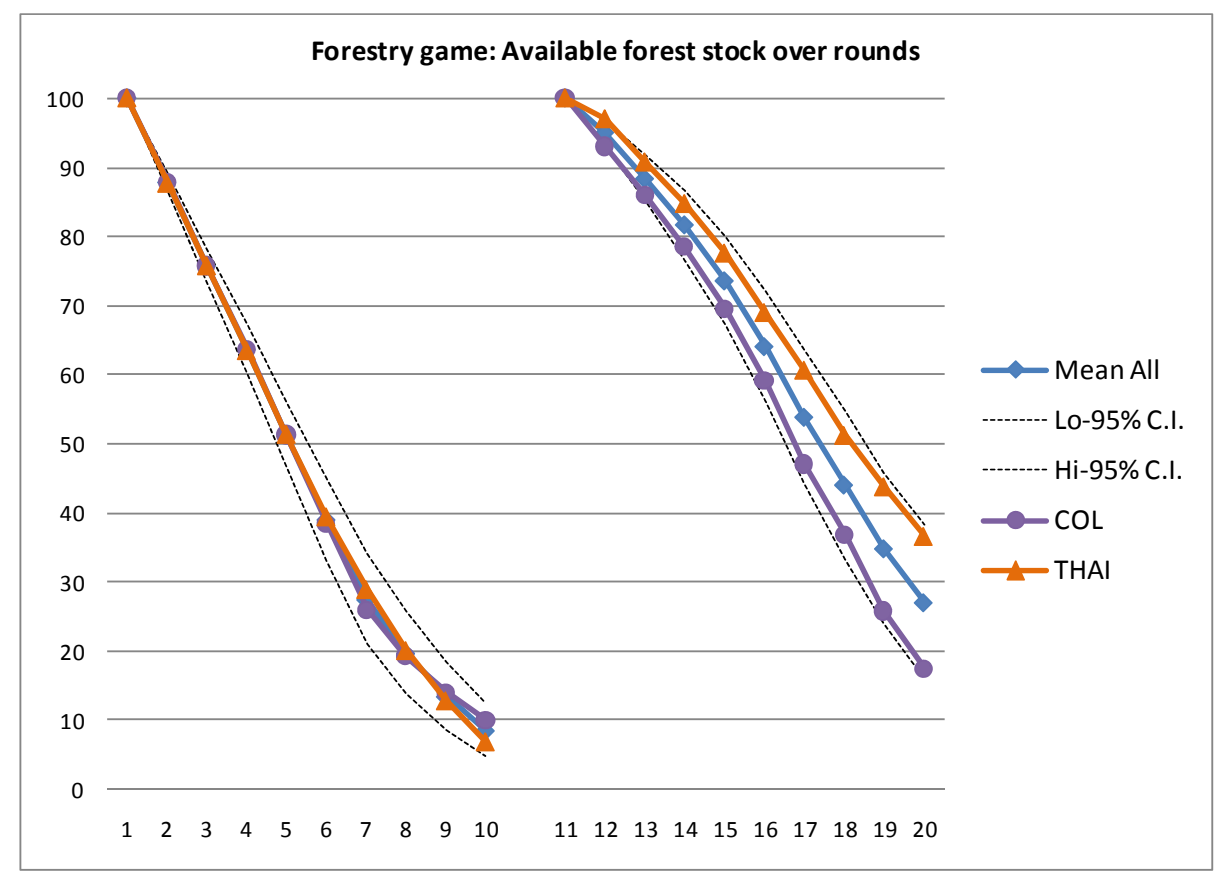

Figure 3. Available forest stock over rounds (Forestry game).

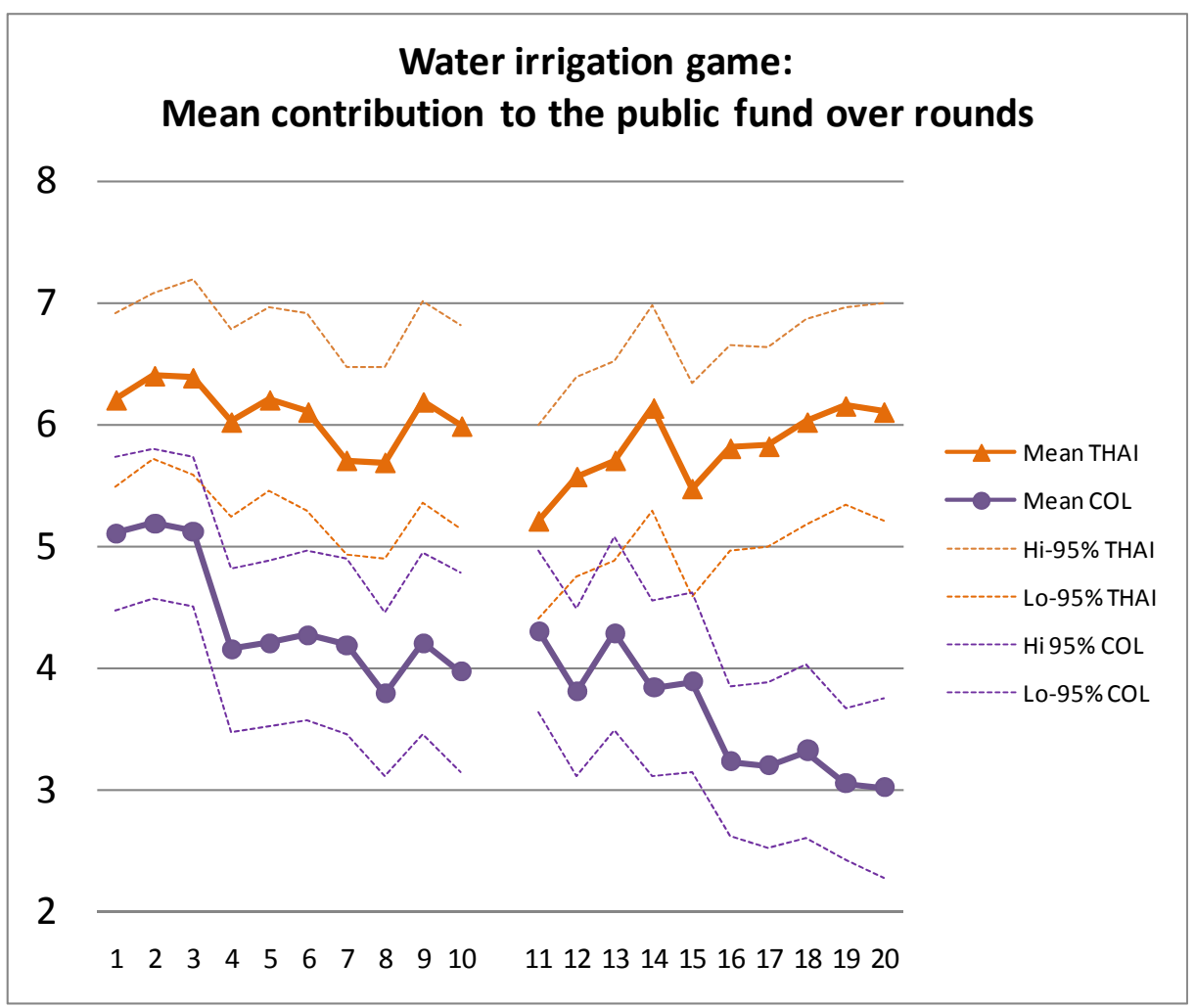

Figure 4. Contributions to the public fund (Water Irrigation game) 


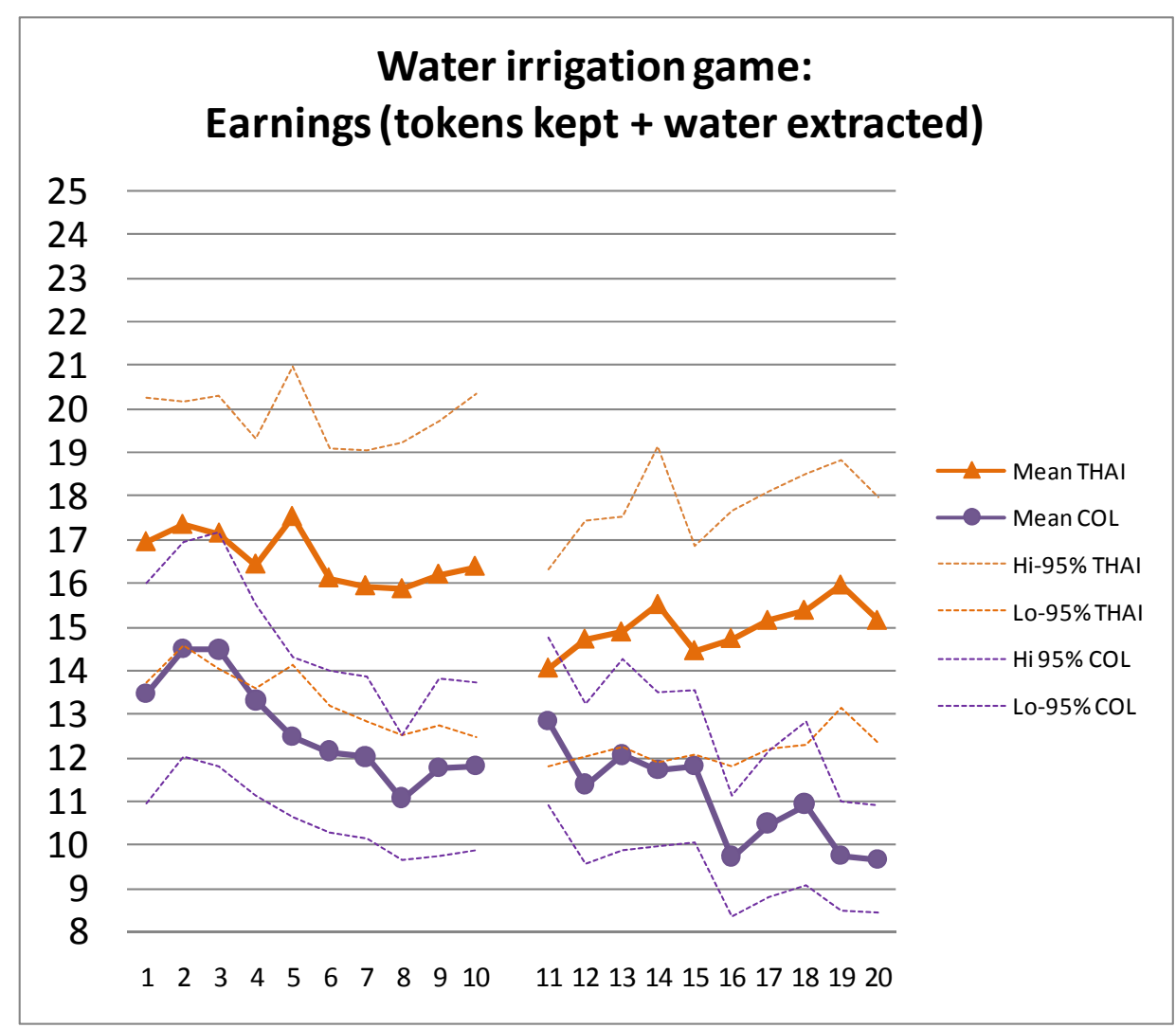

Figure 5. Earnings (tokens kept and water extracted). (Water Irrigation Game).

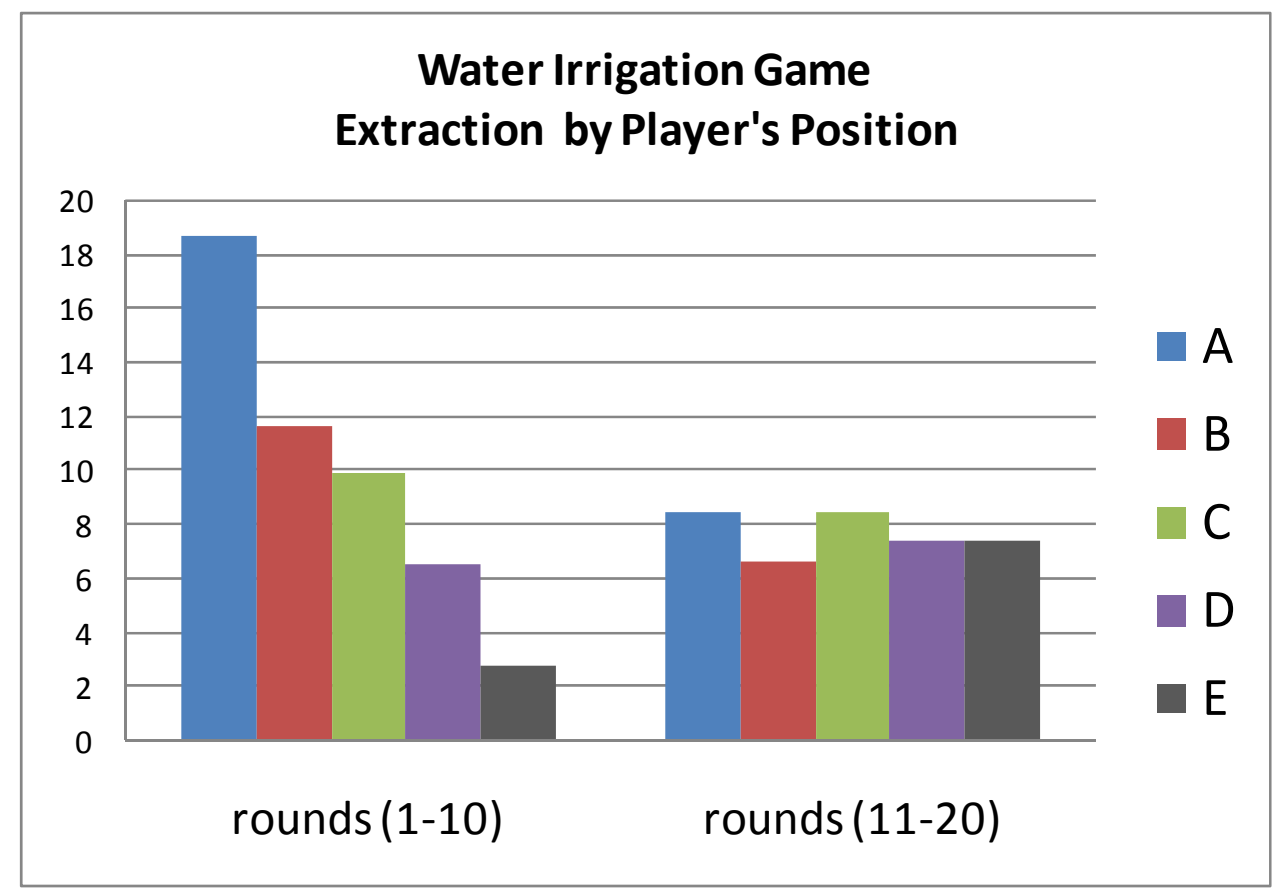

Figure 6. Water extraction by location in the watershed (Water Irrigation Game). 


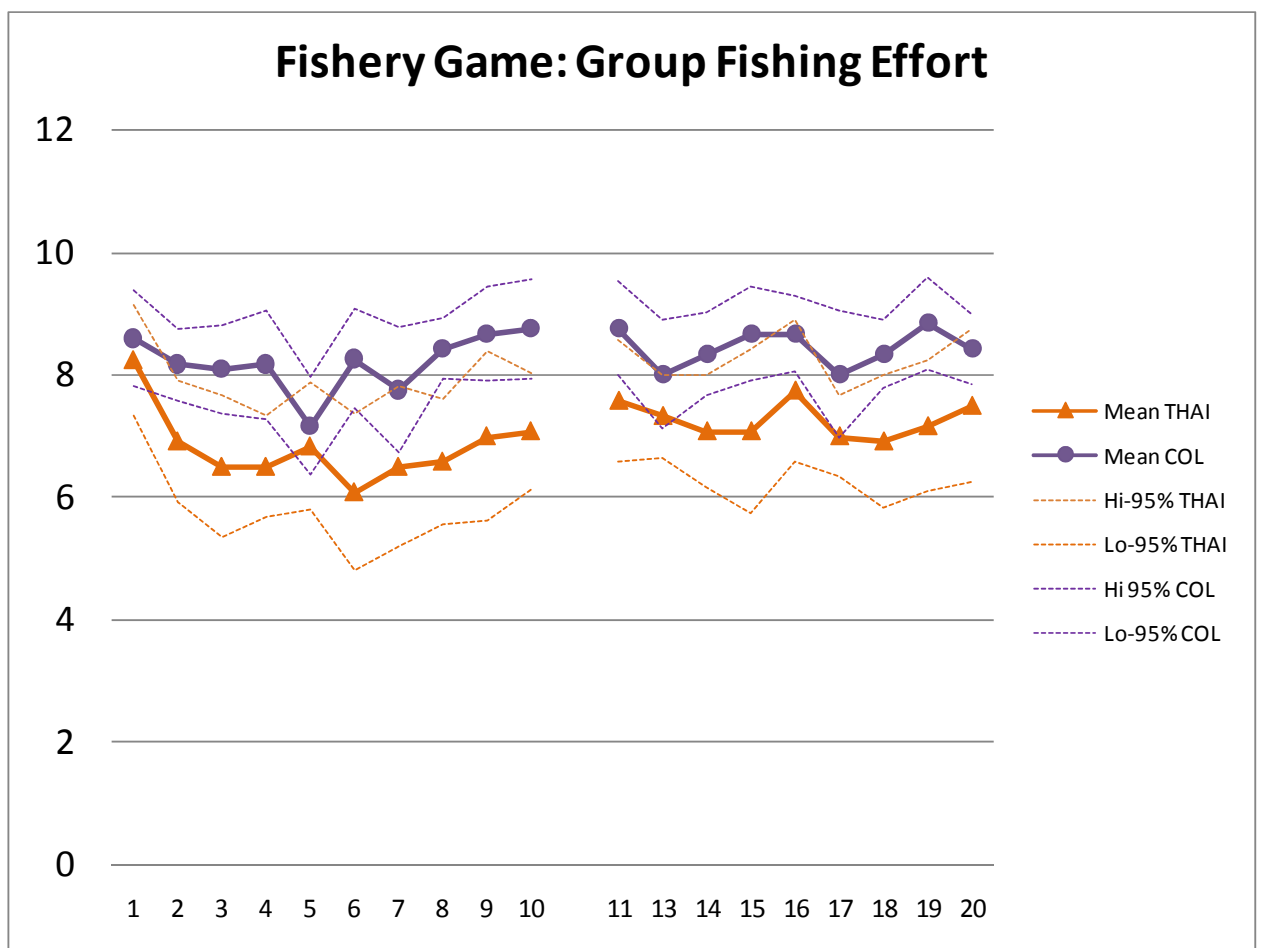

Figure 7. Group fishing effort (Fishery game)

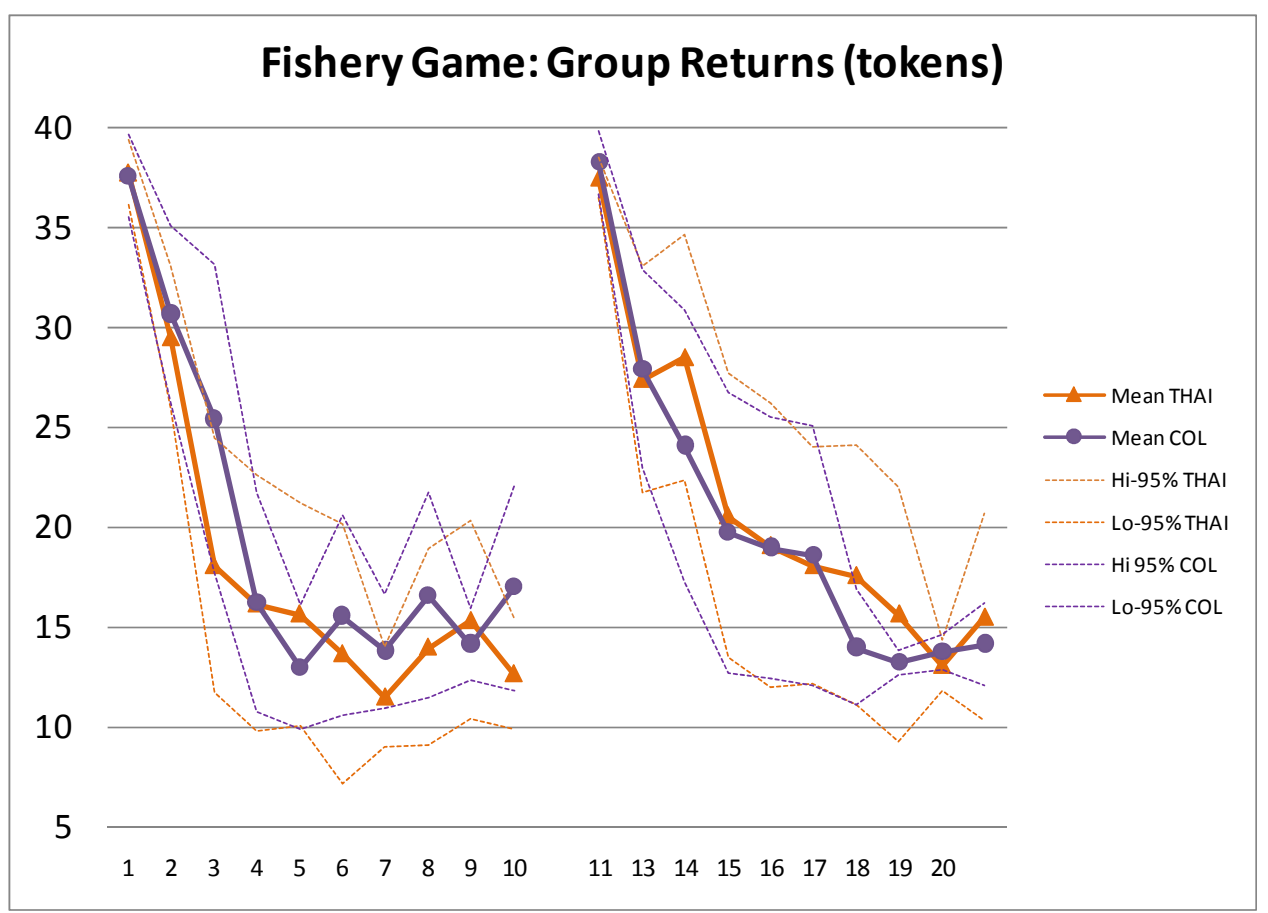

Figure 8. Group earnings (Fishery game) 


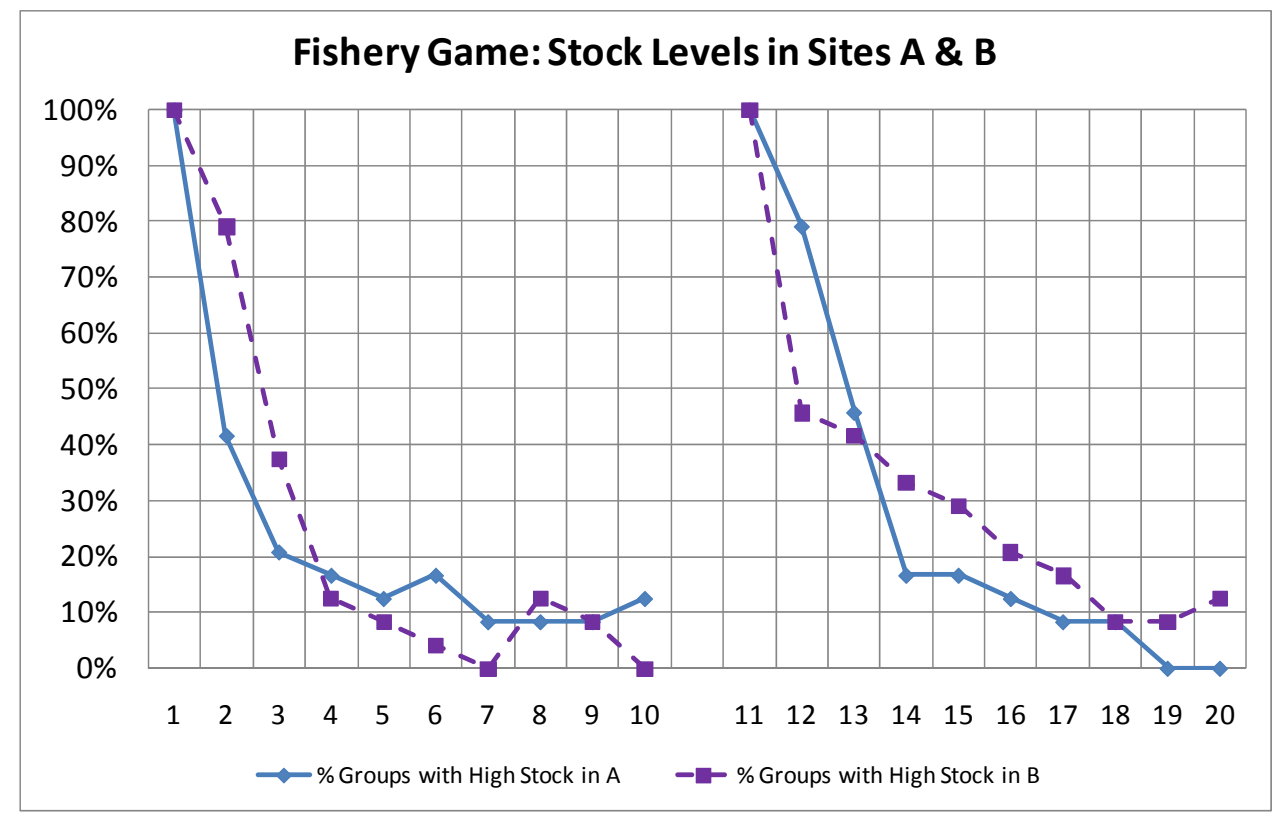

Figure 9. Stock levels in sites A and B (Fishery game) 
Tables.

\begin{tabular}{|c|c|c|c|c|}
\hline Sample & $\begin{array}{l}\text { Fishery } \\
\text { Village }\end{array}$ & $\begin{array}{l}\text { Irrigation } \\
\text { Village }\end{array}$ & $\begin{array}{l}\text { Forestry } \\
\text { Village }\end{array}$ & TOTAL \\
\hline $\begin{array}{l}\text { Fishery } \\
\text { game }\end{array}$ & $\begin{array}{l}20 \text { Colombia } \\
20 \text { Thailand }\end{array}$ & $\begin{array}{l}20 \text { Colombia } \\
20 \text { Thailand }\end{array}$ & $\begin{array}{l}20 \text { Colombia } \\
20 \text { Thailand }\end{array}$ & 120 \\
\hline $\begin{array}{l}\text { Irrigation } \\
\text { game }\end{array}$ & $\begin{array}{l}20 \text { Colombia } \\
20 \text { Thailand }\end{array}$ & $\begin{array}{l}20 \text { Colombia } \\
20 \text { Thailand }\end{array}$ & $\begin{array}{l}20 \text { Colombia } \\
20 \text { Thailand }\end{array}$ & 120 \\
\hline $\begin{array}{l}\text { Forestry } \\
\text { game }\end{array}$ & $\begin{array}{l}20 \text { Colombia } \\
20 \text { Thailand }\end{array}$ & $\begin{array}{l}20 \text { Colombia } \\
20 \text { Thailand }\end{array}$ & $\begin{array}{l}20 \text { Colombia } \\
20 \text { Thailand }\end{array}$ & 120 \\
\hline TOTAL & $\begin{array}{l}120 \text { people } \\
24 \text { sessions }\end{array}$ & $\begin{array}{l}120 \text { people } \\
24 \text { sessions }\end{array}$ & $\begin{array}{l}120 \text { people } \\
24 \text { sessions }\end{array}$ & $\begin{array}{l}360 \text { people } \\
72 \text { sessions }\end{array}$ \\
\hline
\end{tabular}

Table 1. Experimental design and sample.

\begin{tabular}{|c|c|}
\hline \multicolumn{2}{|c|}{ Maximum harvest table } \\
\hline Level & $\begin{array}{c}\text { Individual } \\
\text { Maximum } \\
\text { harvest } \\
\text { level }\end{array}$ \\
\hline $25-100$ & 5 \\
\hline $20-24$ & 4 \\
\hline $15-19$ & 3 \\
\hline $10-14$ & 2 \\
\hline $5-9$ & 1 \\
\hline $0-4$ & 0 \\
\hline
\end{tabular}

Table 2. Maximum harvest allowed (Forestry game) 


\begin{tabular}{|c|c|}
\hline \multicolumn{2}{|c|}{ Table of available water quantity } \\
\hline $\begin{array}{c}\text { Total units invested } \\
\text { by all 5 players }\end{array}$ & $\begin{array}{c}\text { Water } \\
\text { available }\end{array}$ \\
\hline $0-10$ & 0 \\
\hline $11-15$ & 5 \\
\hline $16-20$ & 20 \\
\hline $21-25$ & 40 \\
\hline $26-30$ & 60 \\
\hline $31-35$ & 75 \\
\hline $36-40$ & 85 \\
\hline $41-45$ & 95 \\
\hline $46-50$ & 100 \\
\hline
\end{tabular}

Table 3. Water production as a function of units invested in public fund (Water game)

\begin{tabular}{|r|c|c|c|}
\hline \multicolumn{4}{|c|}{ Payoff table } \\
\hline $\begin{array}{l}\text { Fish } \\
\text { available in } \\
\text { location }\end{array}$ & 0 & 1 & 2 \\
\cline { 2 - 4 } High & 0 & 7 & 8 \\
\hline Low & 0 & 2 & 3 \\
\hline
\end{tabular}

Table 4. Returns (tokens) from effort and fish availability in one location (Fishery game) 